\title{
A Multibody Model of Tilt-Rotor Aircraft Based on Kane's Method
}

\author{
Jianmin Su $\mathbb{D},{ }^{1}$ Chengyue Su $\mathbb{D},{ }^{1}$ Sheng $X u\left(\mathbb{D},{ }^{1}\right.$ and Xiaoxing Yang $\mathbb{D}^{2}$ \\ ${ }^{1}$ School of Physics and Optoelectronic Engineering, Guangdong University of Technology, No. 100, West Ring Road, University Town, \\ Guangzhou, 510006, China \\ ${ }^{2}$ School of Data and Computer Science, Sun Yat-sen University, No. 132, Outer Ring Road East, University Town, Guangzhou, \\ 510006, China
}

Correspondence should be addressed to Chengyue Su; cysu@gdut.edu.cn

Received 6 September 2018; Revised 29 December 2018; Accepted 9 January 2019; Published 16 April 2019

Academic Editor: Paul Williams

Copyright (C) 2019 Jianmin Su et al. This is an open access article distributed under the Creative Commons Attribution License, which permits unrestricted use, distribution, and reproduction in any medium, provided the original work is properly cited.

\begin{abstract}
A tilt-rotor aircraft can switch between two flight configurations (the helicopter configuration and the fixed-wing plane configuration) by tilting its rotors. In the process of rotor tilting, the nacelles which drive the rotors tilt together with the rotors. Because the mass of the nacelles cannot be ignored compared to the mass of the whole aircraft, the tilting of the nacelles is a coupling motion of the body and the nacelles. In order to better character the aircraft dynamics during the nacelle tilting, a multibody model is established in this paper. In this multibody model, Kane's method is used to build a dynamic model of a tilt-rotor aircraft. The generalized rates are used to describe the movement of the body and the nacelles (with rotors). The generalized active forces and generalized inertial forces of both the body and the nacelles (with rotors) are obtained, respectively, and the first-order differential equations of the generalized rates are obtained. The longitudinal trim of the XV15 aircraft is calculated according to the single-body model and our multibody model, in this paper, and the results verify the correctness of the multibody model. In the process of nacelle inclination angle command tracking, the multibody model can provide more information about the disturbance torque of the nacelle than the single-body model, and model inversion control based on the proposed multibody model can obtain a better tracking result than a PID control method only using nacelle angle feedback information.
\end{abstract}

\section{Introduction}

A tilt-rotor aircraft makes its flight configuration switch between the helicopter configuration and the fixed-wing airplane configuration by changing the direction of the rotor thrust. The tilting of the nacelles (with rotors) distinguishes the tilt-rotor aircraft from a helicopter or fixedwing airplane, so tilt-rotor aircraft modeling should consider the process of the tilting of the nacelles. Because the mass of the nacelles (with rotors) cannot be ignored compared to the mass of the tilt-rotor aircraft, tilting of the nacelles (with rotors) will lead to the following features: (1) significant changes of both the center of gravity (c.g.) position and the moment of inertia of the tilt-rotor aircraft and (2) an interaction between the nacelles (with rotors) and the body of the tilt-rotor aircraft. These features make the dynamic model of the tilt-rotor aircraft more complicated.
Rosenstein et al. [1] established a mathematical model for a real-time simulation of a tilt-rotor aircraft (Boeing Vertol Model 222). In their work, the angular momentums of the body and the nacelles were added together to get the angular momentum of the tilt-rotor aircraft with respect to the tilt-rotor aircraft c.g. in the body axis, and the angular momentum theorem was used to obtain the dynamic model of the tilt-rotor aircraft. Ferguson [2] established a generic tilt-rotor aircraft model (GTRS), and the differential equations of motion variables were the same as that in Ref. [1]. Miller et al. used d'Alembert's principle to establish the dynamic equations of a tilt-rotor aircraft [3]. Li et al. reckoned the body, the nacelles, and the rotors to be independent entities and established a realistic model in the form of multibody motion equations [4].

A numerical simulation model including the rotor, the wing, and the nacelle was built using a general purpose multibody simulation tool to study active control 
technology for tilt-rotor aircraft whirl flutter stability augmentation [5]. A simplified aeroelastic tilt-rotor model was built to analyze the vertical bounce phenomenon [6]. Multibody models of a tilt-rotor aircraft were implemented using the free multibody analysis software MBDyn in Politecnico di Milano. Aerodynamic loads were modeled for the wing and the rotor. The detailed control system kinematics and compliance were modeled. The overall multibody model consisted of more than 800 equations $[7,8]$.

Neural network-augmented model inversion control was used to provide a tilt-rotor aircraft with consistent response characteristics throughout its operating envelope [9]. Multiple model inversion controllers were designed at different flight conditions, and mode switching technology was adopted to guarantee smoothly the transition between the controllers [10]. Model predictive control was used to design a tilt-rotor aircraft flight control system and was implemented on a real-time simulator [11]. These control algorithms were verified on a GTRS model. Kim et al. designed the trajectory tracking controller for a tilt-rotor unmanned aerial vehicle based on a neural network-augmented model inversion control method [12]. In the above research on the flight control of the tilt-rotor aircraft, active control for the nacelle tilting is not found. An active control method has been developed for the control of the aeroelasticity and structural dynamics of a tilt-rotor [5]. Bernardini et al. [13] proposed an active control strategy to the alleviation of tonal noise inside the hosting passenger area of a midrange tilt-rotor. Singh et al. [14] examined the effectiveness of active control through wing flaperon and swash plate actuation for the alleviation of whirl-flutter instability of the full-scale XV-15 proprotor on a semispan wing.

In Refs. [1, 2], a tilt-rotor aircraft was treated as a single rigid body, and Euler equations were used to describe the attitude motion. A Euler pitch equation was amended according to the nacelle tilting, and the inclination angle and angular velocity of the nacelles were considered known quantities. Tilting of the nacelles is driven by a motor torque from the body, and it is the sum of the nacelle rotation and the body pitch motion. In order to describe the interaction between the body and the nacelles, a multibody model is established in this paper. In this multibody model, the body and the nacelles can be treated as rigid bodies that are hinged together. Kane's method is a multirigid body modeling method suitable for computer programming. It uses generalized rates instead of generalized coordinates as independent variables to describe the motion of the system, avoiding the cumbersome process of dynamic function derivation [15]. Therefore, in this paper, Kane's method is used to establish the multibody model of a tilt-rotor aircraft. The characteristics of this model are as follows: (1) the final form of the model is not a correction to the rigid body six-degree-of-freedom model, but a dynamic model of multiple rigid bodies; (2) the interaction motor torques between the body and the nacelles are introduced into the model, and the first-order differential equation of the nacelle tilting angular velocity is given; and (3) the derivation process of the model is simple and straightforward, and it is suitable for computer programming.

Using the proposed multibody model, a tilt-rotor aircraft attitude controller based on the model inverse method is designed to make Euler angles and the nacelle inclination angle of the tilt-rotor track commands. A linearized multibody model of a tilt-rotor aircraft at an equilibrium point is used in a model inverse control method. In the tracking of the nacelle inclination angle command near the equilibrium point, the model inverse control is better than a PID control, which does not use any model information.

The following is the arrangement of this paper: In Section 2, the basic assumptions and the definition of coordinate systems are given. Section 3 describes our multibody model of a tilt-rotor aircraft based on Kane's method. In Section 4, we trim the XV-15 tilt-rotor aircraft longitudinally at various speeds based on the multibody model and single-body model. In Section 5, model inversion control is used to make Euler angles and the nacelle inclination angle of a tilt-rotor aircraft track the commands near an equilibrium point. The conclusions of this paper are included in the last section.

\section{Frames and Hypothesis}

A tilt-rotor aircraft consists of the fuselage, wings, rudders, left nacelle, right nacelle, left rotor, and right rotor. Each component is treated as a rigid body. To simplify the problem, we make the following assumptions:

(1) During the transition of the flight configuration of the tilt-rotor aircraft, the left and right nacelles are synchronously tilted

(2) The tilt-rotor aircraft is composed of two rigid bodies, which are the body (including fuselage, wings, and rudders) and the nacelle (including left nacelle, right nacelle, left rotor, and right rotor)

(3) Due to the synchronous tilting of the left and right nacelles, the gyro torques of the left and right rotors offset each other

The coordinates used in this paper are as follows:

(1) Earth-axis system $O_{\mathrm{E}} X_{\mathrm{E}} Y_{\mathrm{E}} Z_{\mathrm{E}}$ : the origin of the Earth axis system is fixed at a point on the ground. The $x$-axis points to the north in the horizontal plane. The $y$-axis is perpendicular to the horizontal plane, and the $z$-axis points the direction of gravity. The Earth axis system is considered the inertial coordinate system

(2) Body axis system $O_{\mathrm{B}} X_{\mathrm{B}} Y_{\mathrm{B}} Z_{\mathrm{B}}$ : the origin of the body axis system is located at the center of gravity of the body. The $x$-axis points forward along the central axis of the body, and the $z$-axis is in the longitudinal plane of symmetry of the body. The $y$-axis follows the right-hand rule

(3) Nacelle axis system $O_{\mathrm{N}} X_{\mathrm{N}} Y_{\mathrm{N}} Z_{\mathrm{N}}$ : the origin of the nacelle axis system is located at the center of gravity of the nacelle. The direction of the $x$-axis is the same as the thrust of the rotors. The direction of the $y$-axis is the same as the shaft of the nacelle, and the $z$-axis follows the right-hand rule

The body axis system and nacelle axis system are shown in Figure 1. Point $P$ is the joint point of the body and the nacelle, and $\theta_{\mathrm{N}}$ is the inclination angle of the nacelle. 


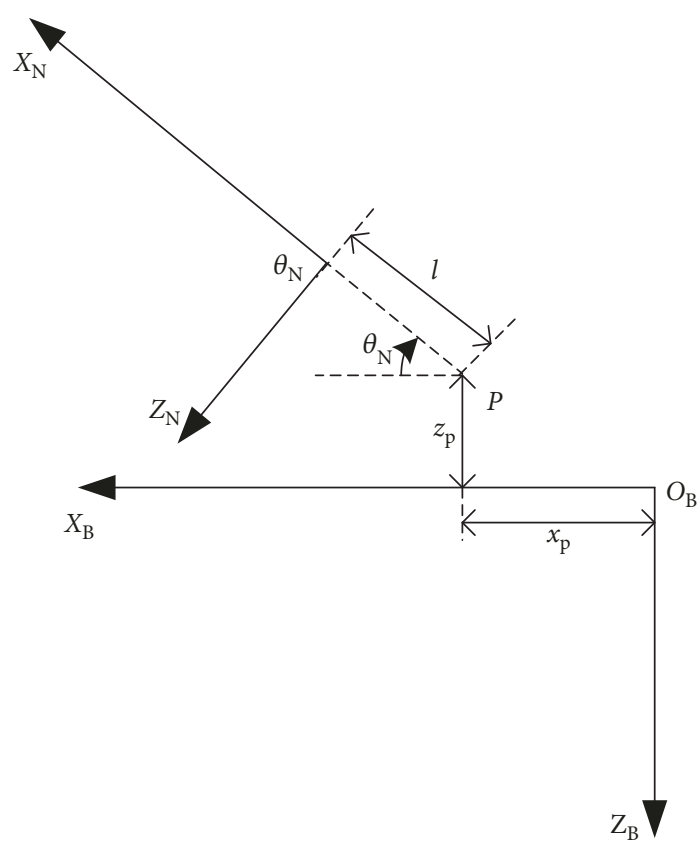

FIgure 1: Coordinate system diagram.

\section{Multibody Model Based on Kane's Method}

In this section, a multibody model of a tilt-rotor aircraft is deduced using Kane's method based on the assumptions in the last section. Firstly, generalized rates are selected to describe the motions of the body and the nacelle. The relationship of generalized rates and the change rates of both the body Euler angles and the nacelle inclination angle is established. Secondly, the translation motion and angular motion of both the body and the nacelle are represented as generalized rates. Thirdly, partial velocities and partial angular velocities of both the body and the nacelle are deduced, and the generalized active forces and the generalized inertial forces of both the body and the nacelle are deduced. Firstorder differential equations for generalized rates are deduced based on Kane's equation.

3.1. Generalized Rates and Kinematic Equations. Seven generalized rates $u, v, w, p, q, r$, and $\omega$ are selected to describe the motion of the tilt-rotor aircraft, in which $u, v$, and $w$ are the translational velocities of the body c.g., $p, q$, and $r$ are the body angular velocities, and $\omega$ is the tilting speed of the nacelle relative to the body.

The Euler angles $\phi, \theta$, and $\psi$ are attitude angles of the body relative to the Earth-axis system. The first derivative of the Euler angles and nacelle inclination angle with regard to time is shown in

$$
\left\{\begin{array}{l}
\dot{\phi}=p+\tan \theta(q \sin \phi+r \cos \phi), \\
\dot{\theta}=q \cos \phi-r \sin \phi, \\
\dot{\psi}=\frac{q \sin \phi+r \cos \phi}{\cos \theta}, \\
\dot{\theta}_{\mathrm{N}}=\omega .
\end{array}\right.
$$

3.2. Motions of the Body and the Nacelle. According to the geometric relationship between the body and the nacelle (see Figure 1), the kinematics of the body and nacelle can be represented as the generalized rates.

The body c.g. translation velocity $v_{\mathrm{B}}$ is $(u, v, w)$, and the body angular velocity $\omega_{\mathrm{B}}$ is $(p, q, r)$. The body c.g. translation acceleration $a_{\mathrm{B}}$ is given in

$$
a_{\mathrm{B}}=\frac{d v_{\mathrm{B}}}{d t}=\frac{\delta v_{\mathrm{B}}}{d t}+\omega_{\mathrm{B}} \times v_{\mathrm{B}} .
$$

The various terms of equation (2) are, in a component form,

$$
\begin{gathered}
\frac{\delta v_{\mathrm{B}}}{d t}=(\dot{u}, \dot{v}, \dot{w}), \\
\omega_{\mathrm{B}} \times v_{\mathrm{B}}=(q w-r v, r u-p w, p v-q u) .
\end{gathered}
$$

The body angular acceleration $\varepsilon_{\mathrm{B}}$ is $(\dot{p}, \dot{q}, \dot{r})$.

The nacelle c.g. translation velocity $v_{\mathrm{N}}$ is given in

$$
v_{\mathrm{N}}=v_{\mathrm{B}}+\frac{\delta r_{\mathrm{PO}_{\mathrm{N}}}}{\delta t}+\omega_{\mathrm{B}} \times\left(r_{\mathrm{O}_{\mathrm{B}} \mathrm{P}}+r_{\mathrm{PO}_{\mathrm{N}}}\right),
$$

where

$$
\begin{aligned}
r_{\mathrm{PO}_{\mathrm{N}}} & =\left(l \cos \theta_{\mathrm{N}}, 0,-l \sin \theta_{\mathrm{N}}\right), \\
\frac{\delta r_{\mathrm{PO}_{\mathrm{N}}}}{\delta t} & =\left(-l \omega \sin \theta_{\mathrm{N}}, 0,-l \omega \cos \theta_{\mathrm{N}}\right), \\
r_{\mathrm{O}_{\mathrm{B}} \mathrm{P}} & =\left(x_{\mathrm{p}}, 0, z_{\mathrm{p}}\right) .
\end{aligned}
$$

The nacelle angular velocity $\omega_{\mathrm{N}}$ is $(p, q+\omega, r)$.

The nacelle c.g. translation acceleration $a_{\mathrm{N}}$ is given in

$$
\begin{aligned}
a_{\mathrm{N}}= & a_{\mathrm{B}}+\frac{\delta^{2} r_{\mathrm{PO}_{\mathrm{N}}}}{\delta t^{2}}+\varepsilon_{\mathrm{B}} \times\left(r_{\mathrm{O}_{\mathrm{B}} \mathrm{P}}+r_{\mathrm{PO}_{\mathrm{N}}}\right)+\omega_{\mathrm{B}} \\
& \times\left[\omega_{\mathrm{B}} \times\left(r_{\mathrm{O}_{\mathrm{B}} \mathrm{P}}+r_{\mathrm{PO}_{\mathrm{N}}}\right)\right]+2 \omega_{\mathrm{B}} \times \frac{\delta r_{\mathrm{PO}_{\mathrm{N}}}}{\delta t},
\end{aligned}
$$

where

$\frac{\delta^{2} r_{\mathrm{PO}_{\mathrm{N}}}}{\delta t^{2}}=\left(-l\left(\omega^{2} \cos \theta_{\mathrm{N}}+\dot{\omega} \sin \theta_{\mathrm{N}}\right), 0,-l\left(-\omega^{2} \sin \theta_{\mathrm{N}}+\dot{\omega} \cos \theta_{\mathrm{N}}\right)\right)$.

The nacelle angular acceleration $\varepsilon_{\mathrm{N}}$ is given in

$$
\varepsilon_{\mathrm{N}}=\varepsilon_{\mathrm{B}}+\frac{\delta \omega_{\mathrm{r}}}{\delta t}+\omega_{\mathrm{B}} \times \omega_{\mathrm{r}}
$$

where

$$
\begin{aligned}
\omega_{\mathrm{r}} & =(0, \omega, 0), \\
\frac{\delta \omega_{\mathrm{r}}}{\delta t} & =(0, \dot{\omega}, 0) .
\end{aligned}
$$

3.3. First-Order Differential Equations for Generalized Rates. The body's partial velocities $v_{\mathrm{B}}^{i}$ and angular velocities $\omega_{\mathrm{B}}^{i}$ 
and the nacelle's partial velocities $v_{\mathrm{N}}^{i}$ and angular velocities $\omega_{\mathrm{N}}^{i}$ for each generalized rate are as follows:

$v_{\mathrm{B}}^{1}=\frac{\partial v_{\mathrm{B}}}{\partial u}, v_{\mathrm{B}}^{2}=\frac{\partial v_{\mathrm{B}}}{\partial v}, v_{\mathrm{B}}^{3}=\frac{\partial v_{\mathrm{B}}}{\partial w}, v_{\mathrm{B}}^{4}=\frac{\partial v_{\mathrm{B}}}{\partial p}, v_{\mathrm{B}}^{5}=\frac{\partial v_{\mathrm{B}}}{\partial q}$,

$v_{\mathrm{B}}^{6}=\frac{\partial v_{\mathrm{B}}}{\partial r}, v_{\mathrm{B}}^{7}=\frac{\partial v_{\mathrm{B}}}{\partial \omega}, \omega_{\mathrm{B}}^{1}=\frac{\partial \omega_{\mathrm{B}}}{\partial u}, \omega_{\mathrm{B}}^{2}=\frac{\partial \omega_{\mathrm{B}}}{\partial v}, \omega_{\mathrm{B}}^{3}=\frac{\partial \omega_{\mathrm{B}}}{\partial w}$,

$\omega_{\mathrm{B}}^{4}=\frac{\partial \omega_{\mathrm{B}}}{\partial p}, \omega_{\mathrm{B}}^{5}=\frac{\partial \omega_{\mathrm{B}}}{\partial q}, \omega_{\mathrm{B}}^{6}=\frac{\partial \omega_{\mathrm{B}}}{\partial r}, \omega_{\mathrm{B}}^{7}=\frac{\partial \omega_{\mathrm{B}}}{\partial \omega}, v_{\mathrm{N}}^{1}=\frac{\partial v_{\mathrm{N}}}{\partial u}$,

$v_{\mathrm{N}}^{2}=\frac{\partial v_{\mathrm{N}}}{\partial v}, v_{\mathrm{N}}^{3}=\frac{\partial v_{\mathrm{N}}}{\partial w}, v_{\mathrm{N}}^{4}=\frac{\partial v_{\mathrm{N}}}{\partial p}, v_{\mathrm{N}}^{5}=\frac{\partial v_{\mathrm{N}}}{\partial q}, v_{\mathrm{N}}^{6}=\frac{\partial v_{\mathrm{N}}}{\partial r}$,

$v_{\mathrm{N}}^{7}=\frac{\partial v_{\mathrm{N}}}{\partial \omega}, \omega_{\mathrm{N}}^{1}=\frac{\partial \omega_{\mathrm{N}}}{\partial u}, \omega_{\mathrm{N}}^{2}=\frac{\partial \omega_{\mathrm{N}}}{\partial v}, \omega_{\mathrm{N}}^{3}=\frac{\partial \omega_{\mathrm{N}}}{\partial w}, \omega_{\mathrm{N}}^{4}=\frac{\partial \omega_{\mathrm{N}}}{\partial p}$,

$\omega_{\mathrm{N}}^{5}=\frac{\partial \omega_{\mathrm{N}}}{\partial q}, \omega_{\mathrm{N}}^{6}=\frac{\partial \omega_{\mathrm{N}}}{\partial r}, \omega_{\mathrm{N}}^{7}=\frac{\partial \omega_{\mathrm{N}}}{\partial \omega}$.

The sum of all the forces acting on the body (excluding the force exerted by the nacelle) is as follows:

$$
F_{\mathrm{B}}=\left(\begin{array}{c}
f_{\mathrm{B} x} \\
f_{\mathrm{B} y} \\
f_{\mathrm{B} z}
\end{array}\right)=F_{\mathrm{f}}+F_{\mathrm{w}}+F_{\mathrm{t}}+G_{\mathrm{B}},
$$

where $F_{\mathrm{f}}$ is the aerodynamic force of the fuselage, $F_{\mathrm{w}}$ is the aerodynamic force of the wings, $F_{\mathrm{t}}$ is the aerodynamic force of the tails, and $G_{\mathrm{B}}$ is the gravity force of the body. The sum of all torques acting on the body (relative to the body's c.g.) is as follows:

$$
M_{\mathrm{B}}=\left(\begin{array}{c}
m_{\mathrm{B} x} \\
m_{\mathrm{B} y} \\
m_{\mathrm{B} z}
\end{array}\right)=M_{\mathrm{f}}+M_{\mathrm{w}}+M_{\mathrm{t}}-M_{\mathrm{c}} \text {, }
$$

where $M_{\mathrm{f}}$ is the aerodynamic torque of the fuselage, $M_{\mathrm{w}}$ is the aerodynamic torque of the wings, $M_{\mathrm{t}}$ is the aerodynamic torque of the tails, and $M_{c}=\left(0, m_{c}, 0\right)^{\mathrm{T}}$ is the motor torque act on the nacelle. The sum of all the forces acting on the nacelle (excluding the force exerted by the body) is as follows:

$$
F_{\mathrm{N}}=\left(\begin{array}{c}
f_{\mathrm{N} x} \\
f_{\mathrm{N} y} \\
f_{\mathrm{N} z}
\end{array}\right)=F_{\mathrm{Rr}}+F_{\mathrm{Rl}}+G_{\mathrm{N}},
$$

where $F_{\mathrm{Rr}}$ is the aerodynamic force of the right rotor, $F_{\mathrm{Rl}}$ is the aerodynamic force of the left rotor, and $G_{\mathrm{N}}$ is the gravity force of the nacelle. The sum of all torques acting on the nacelle (relative to the nacelle's c.g.) is as follows:

$$
M_{\mathrm{N}}=\left(\begin{array}{c}
m_{\mathrm{N} x} \\
m_{\mathrm{N} y} \\
m_{\mathrm{N} z}
\end{array}\right)=M_{\mathrm{Rr}}+M_{\mathrm{Rl}}+M_{\mathrm{c}},
$$

where $M_{\mathrm{Rr}}$ is the aerodynamic torque of the right rotor and $M_{\mathrm{Rl}}$ is the aerodynamic torque of the left rotor.

The generalized active forces of the tilt-rotor aircraft are as follows:

$$
f_{j}=F_{\mathrm{B}} \cdot v_{\mathrm{B}}^{j}+M_{\mathrm{B}} \cdot \omega_{\mathrm{B}}^{j}+F_{\mathrm{N}} \cdot v_{\mathrm{N}}^{j}+M_{\mathrm{N}} \cdot \omega_{\mathrm{N}}^{j}, \quad j=1,2, \ldots, 7,
$$

and the generalized inertial forces of the tilt-rotor aircraft are as follows:

$$
f_{j}^{*}=F_{\mathrm{B}}^{*} \cdot v_{\mathrm{B}}^{j}+M_{\mathrm{B}}^{*} \cdot \omega_{\mathrm{B}}^{j}+F_{\mathrm{N}}^{*} \cdot v_{\mathrm{N}}^{j}+M_{\mathrm{N}}^{*} \cdot \omega_{\mathrm{N}}^{j}, \quad j=1,2, \ldots, 7,
$$

where

$$
\begin{aligned}
F_{\mathrm{B}}^{*} & =m_{\mathrm{B}} a_{\mathrm{B}}, \\
M_{\mathrm{B}}^{*} & =I_{\mathrm{B}} \varepsilon_{\mathrm{B}}+\omega_{\mathrm{B}} \times I_{\mathrm{B}} \omega_{\mathrm{B}}, \\
F_{\mathrm{N}}^{*} & =m_{\mathrm{N}} a_{\mathrm{N}}, \\
M_{\mathrm{N}}^{*} & =I_{\mathrm{N}} \varepsilon_{\mathrm{N}}+\omega_{\mathrm{N}} \times I_{\mathrm{N}} \omega_{\mathrm{N}} .
\end{aligned}
$$

The following equation is the moment of the inertia matrix of the body.

$$
I_{\mathrm{B}}=\left[\begin{array}{ccc}
I_{\mathrm{B} x} & 0 & 0 \\
0 & I_{\mathrm{B} y} & 0 \\
0 & 0 & I_{\mathrm{B} z}
\end{array}\right] .
$$

The following equation is the moment of the inertia matrix of the nacelle.

$$
\boldsymbol{I}_{\mathrm{N}}=\left[\begin{array}{ccc}
I_{\mathrm{N} x} & 0 & 0 \\
0 & I_{\mathrm{N} y} & 0 \\
0 & 0 & I_{\mathrm{N} z}
\end{array}\right]
$$

Based on Kane's equation, we have the following formula:

$$
f_{j}-f_{j}^{*}=0, \quad j=1,2, \ldots, 7 .
$$


The following set of first-order differential equations for generalized rates can be derived:

$$
\begin{aligned}
& f_{\mathrm{B} x}+f_{\mathrm{N} x}-m_{\mathrm{B}}(\dot{u}+q w-r v)+m_{\mathrm{N}}\left\{r v-\dot{q}\left(z_{\mathrm{p}}-l \sin \theta_{\mathrm{N}}\right)\right. \\
& -q w-\dot{u}+r\left[r\left(x_{\mathrm{p}}+l \cos \theta_{\mathrm{N}}\right)-p\left(z_{\mathrm{p}}-l \sin \theta_{\mathrm{N}}\right)\right] \\
& +l\left(\omega^{2} \cos \theta_{\mathrm{N}}+\dot{\omega} \sin \theta_{\mathrm{N}}\right)+q^{2}\left(x_{\mathrm{p}}+l \cos \theta_{\mathrm{N}}\right) \\
& \left.+2 \omega l q \cos \theta_{\mathrm{N}}\right\}=0 \text {, } \\
& f_{\mathrm{B} y}+f_{\mathrm{N} y}-m_{\mathrm{B}}(\dot{v}-p w+r u)-m_{\mathrm{N}}\left\{\dot{v}-\dot{p}\left(z_{\mathrm{p}}-l \sin \theta_{\mathrm{N}}\right)\right. \\
& -p w+r u+\dot{r}\left(x_{\mathrm{p}}+l \cos \theta_{\mathrm{N}}\right) \\
& +p q\left(x_{\mathrm{p}}+l \cos \theta_{\mathrm{N}}\right)+q r\left(z_{\mathrm{p}}-l \sin \theta_{\mathrm{N}}\right) \\
& \left.+2 \omega l p \cos \theta_{\mathrm{N}}-2 \omega l r \sin \theta_{\mathrm{N}}\right\}=0, \\
& f_{\mathrm{B} z}+f_{\mathrm{N} z}-m_{\mathrm{B}}(\dot{w}+p v-q u)-m_{\mathrm{N}}\{\dot{w}+p v-q u \\
& +p\left[r\left(x_{\mathrm{p}}+l \cos \theta_{\mathrm{N}}\right)-p\left(z_{\mathrm{p}}-l \sin \theta_{\mathrm{N}}\right)\right] \\
& -l\left(-\omega^{2} \sin \theta_{\mathrm{N}}+\dot{\omega} \cos \theta_{\mathrm{N}}\right)-q^{2}\left(z_{\mathrm{p}}-l \sin \theta_{\mathrm{N}}\right) \\
& \left.-\dot{q}\left(x_{\mathrm{p}}+l \cos \theta_{\mathrm{N}}\right)+2 \omega l q \sin \theta_{\mathrm{N}}\right\}=0, \\
& m_{\mathrm{B} x}+m_{\mathrm{N} x}-I_{\mathrm{B} x} \dot{p}-I_{\mathrm{N} x}(\dot{p}-\omega r)-f_{\mathrm{N} y}\left(z_{\mathrm{p}}-l \sin \theta_{\mathrm{N}}\right) \\
& +I_{\mathrm{N} y} r(\omega+q)-I_{\mathrm{N} z} r(\omega+q)+I_{\mathrm{B} y} q r-I_{\mathrm{B} z} q r \\
& +m_{\mathrm{N}}\left(z_{\mathrm{p}}-l \sin \theta_{\mathrm{N}}\right)\left[\dot{v}-\dot{p}\left(z_{\mathrm{p}}-l \sin \theta_{\mathrm{N}}\right)-p w+r u\right. \\
& +\dot{r}\left(x_{p}+l \cos \theta_{\mathrm{N}}\right)+q r\left(z_{\mathrm{p}}-l \sin \theta_{\mathrm{N}}\right)+2 \omega l p \cos \theta_{\mathrm{N}} \\
& \left.-2 \omega l r \sin \theta_{\mathrm{N}}\right]=0 \text {, } \\
& m_{\mathrm{B} y}+m_{\mathrm{N} y}-I_{\mathrm{B} y} \dot{q}-I_{\mathrm{N} y}(\dot{\omega}+\dot{q})-f_{\mathrm{N} z}\left(x_{\mathrm{p}}+l \cos \theta_{\mathrm{N}}\right) \\
& +f_{\mathrm{N} x}\left(z_{\mathrm{p}}-l \sin \theta_{\mathrm{N}}\right)-I_{\mathrm{B} x} p r-I_{\mathrm{N} x} p r+I_{\mathrm{B} z} p r+I_{\mathrm{N} z} p r \\
& +m_{\mathrm{N}}\left(x_{\mathrm{p}}+l \cos \theta_{\mathrm{N}}\right)\left\{\dot{w}+p v-q u+p\left[r\left(x_{\mathrm{p}}+l \cos \theta_{\mathrm{N}}\right)\right.\right. \\
& \left.-p\left(z_{\mathrm{p}}-l \sin \theta_{\mathrm{N}}\right)\right]-l\left(-\omega^{2} \sin \theta_{\mathrm{N}}+\dot{\omega} \cos \theta_{\mathrm{N}}\right) \\
& \left.-q^{2}\left(z_{\mathrm{p}}-l \sin \theta_{\mathrm{N}}\right)-\dot{q}\left(x_{\mathrm{p}}+l \cos \theta_{\mathrm{N}}\right)+2 \omega l q \sin \theta_{\mathrm{N}}\right\} \\
& +m_{\mathrm{N}}\left(z_{\mathrm{p}}-l \sin \theta_{\mathrm{N}}\right)\left\{r v-\dot{q}\left(z_{\mathrm{p}}-l \sin \theta_{\mathrm{N}}\right)-q \omega-\dot{u}\right. \\
& +r\left[r\left(x_{\mathrm{p}}+l \cos \theta_{\mathrm{N}}\right)-p\left(z_{\mathrm{p}}-l \sin \theta_{\mathrm{N}}\right)\right] \\
& +l\left(\omega^{2} \cos \theta_{\mathrm{N}}+\dot{\omega} \sin \theta_{\mathrm{N}}\right)+q^{2}\left(x_{\mathrm{p}}+l \cos \theta_{\mathrm{N}}\right) \\
& \left.+2 \omega l q \cos \theta_{\mathrm{N}}\right\}=0 \text {, } \\
& m_{\mathrm{B} z}+m_{\mathrm{N} z}-I_{\mathrm{B} z} \dot{r}-I_{\mathrm{N} z}(\dot{r}+\omega p)+f_{\mathrm{N} y}\left(x_{\mathrm{p}}+l \cos \theta_{\mathrm{N}}\right) \\
& +I_{\mathrm{N} x} p(\omega+q)-I_{\mathrm{N} y} p(\omega+q)+I_{\mathrm{B} x} p q-I_{\mathrm{B} y} p q \\
& -m_{\mathrm{N}}\left(x_{\mathrm{p}}+l \cos \theta_{\mathrm{N}}\right)\left[\dot{v}-\dot{p}\left(z_{\mathrm{p}}-l \sin \theta_{\mathrm{N}}\right)\right. \\
& -p w+r u+\dot{r}\left(x_{\mathrm{p}}+l \cos \theta_{\mathrm{N}}\right)+p q\left(x_{\mathrm{p}}+l \cos \theta_{\mathrm{N}}\right) \\
& \left.+q r\left(z p-l \sin \theta_{\mathrm{N}}\right)+2 \omega l p \cos \theta_{\mathrm{N}}-2 \omega l r \sin \theta_{\mathrm{N}}\right]=0 \text {, } \\
& m_{\mathrm{N} y}+m_{\mathrm{c}}-I_{\mathrm{N} y}(\dot{\omega}+\dot{q})-I_{\mathrm{N} x} p r+I_{\mathrm{N} z} p r-f_{\mathrm{N} z} l \cos \theta_{\mathrm{N}} \\
& -f_{\mathrm{N} x} l \sin \theta_{\mathrm{N}}+\operatorname{lm}_{\mathrm{N}} \cos \theta_{\mathrm{N}}\{\dot{w}+p v-q u \\
& +p\left[r\left(x_{\mathrm{p}}+l \cos \theta_{\mathrm{N}}\right)-p\left(z_{\mathrm{p}}-l \sin \theta_{\mathrm{N}}\right)\right] \\
& -l\left(-\omega^{2} \sin \theta_{\mathrm{N}}+\dot{\omega} \cos \theta_{\mathrm{N}}\right)-q^{2}\left(z_{\mathrm{p}}-l \sin \theta_{\mathrm{N}}\right) \\
& \left.-\dot{q}\left(x_{\mathrm{p}}+l \cos \theta_{\mathrm{N}}\right)+2 \omega l q \sin \theta_{\mathrm{N}}\right\} \\
& -l m_{\mathrm{N}} \sin \theta_{\mathrm{N}}\left\{r v-\dot{q}\left(z_{\mathrm{p}}-l \sin \theta_{\mathrm{N}}\right)-q w-\dot{u}\right.
\end{aligned}
$$

$$
\begin{aligned}
& +r\left[r\left(x_{\mathrm{p}}+l \cos \theta_{\mathrm{N}}\right)-p\left(z_{\mathrm{p}}-l \sin \theta_{\mathrm{N}}\right)\right] \\
& +l\left(\omega^{2} \cos \theta_{\mathrm{N}}+\dot{\omega} \sin \theta_{\mathrm{N}}\right)+q^{2}\left(x_{\mathrm{p}}+l \cos \theta_{\mathrm{N}}\right) \\
& \left.+2 \omega l q \cos \theta_{\mathrm{N}}\right\}=0 .
\end{aligned}
$$

From equation (21), we can solve $\dot{u}, \dot{v}, \dot{w}, \dot{p}, \dot{q}, \dot{r}$, and $\dot{\omega}$ and combine equation (1) to form the dynamic differential equations of the tilt-rotor aircraft.

Regarding the calculation of the aerodynamic force of a tilt-rotor aircraft, the detailed calculation method is given in Refs. $[1,2,16,17]$, which is not discussed in this paper.

\section{Longitudinal Trim for Steady-State Flight}

In this section, we want to verify the correctness of the proposed multibody model. As we know, for the same tiltrotor aircraft, the longitudinal trim results of a single-body model and multibody model should be the same. Firstly, in helicopter flight configuration, the longitudinal trim results of the single-body model and multibody model are calculated and compared, respectively. Secondly, in order to further verify the correctness of the aerodynamic calculation in the multibody model, we use the multibody model to calculate the longitudinal trim at different nacelle inclination angles and flight speeds.

4.1. Comparison of the Single-Body Model and Multibody Model in Longitudinal Trim. We take the XV-15 tilt-rotor aircraft in Ref. [2] as an example, and the main design parameters of XV-15 are shown in Table 1. The longitudinal trim includes the torque balance at the $y$-axis of body axis system, and the force balance at the $x$-axis and the $z$-axis of body axis system. The variables of trim are the collective pitch of the rotors $\delta_{\text {col }}$, longitudinal stick position $\delta_{\mathrm{loN}}$, Euler pitch angle $\theta$, and motor torque acting on the nacelle $m_{\mathrm{c}}$ of the XV-15. The collective pitch of the rotors $\delta_{\text {col }}$ is used to adjust the thrust forces of the rotors, and it is mainly used to control the vertical motion of the XV-15 at helicopter configuration. The longitudinal stick position $\delta_{\mathrm{loN}}$ is used to change the longitudinal periodic pitch of the rotors and generate the torque at the $y$-axis of the body axis system. The adjustment of the Euler pitch angle $\theta$ balances the $x$-axis component of the forces acting on the XV-15. Motor torque acting on the nacelle $m_{c}$ can keep the nacelle inclination angle at a given value.

The longitudinal trim based on the multibody model can be described as follows: for a stable level flight speed $v_{\mathrm{t}}$ and a fixed nacelle inclination $\theta_{\mathrm{N}}$, the objective is to find the appropriate $\delta_{\mathrm{loN}}, \delta_{\mathrm{col}}, \theta$, and $m_{\mathrm{c}}$ to make $\dot{u}, \dot{w}, \dot{q}$, and $\dot{\omega}$ approach zeros. The default algorithm of the "fmincon" function of "Matlab" software can solve the problem.

For the single-body model, the XV-15 is treated as a single rigid body, and nacelle rotation is not considered when longitudinal trim is calculated. The longitudinal trim means that the sums of forces and moments are zeros in the longitudinal plane of the XV-15. The components of the external force sum are $f_{x}, f_{y}$, and $f_{z}$, and the components of the external torque sum are $m_{x}, m_{y}$, and $m_{z}$. The longitudinal trim 
TABLE 1: XV-15 design parameters.

\begin{tabular}{lc}
\hline Parameter & Value \\
\hline$m_{B}(\mathrm{~kg})$ & 3991.6 \\
$m_{N}(\mathrm{~kg})$ & 1905.1 \\
$x_{p}(\mathrm{~m})$ & 0.1448 \\
$z_{p}(\mathrm{~m})$ & -0.9068 \\
$l(\mathrm{~m})$ & 0.4572 \\
$I_{B x}\left(\mathrm{~kg} \cdot \mathrm{m}^{2}\right)$ & 48895 \\
$I_{B y}\left(\mathrm{~kg} \cdot \mathrm{m}^{2}\right)$ & 55208 \\
$I_{B z}\left(\mathrm{~kg} \cdot \mathrm{m}^{2}\right)$ & 96391 \\
$I_{N x}\left(\mathrm{~kg} \cdot \mathrm{m}^{2}\right)$ & 10153 \\
$I_{N y}\left(\mathrm{~kg} \cdot \mathrm{m}^{2}\right)$ & 2989 \\
$I_{N z}\left(\mathrm{~kg} \cdot \mathrm{m}^{2}\right)$ & 10362 \\
\hline
\end{tabular}

TABLE 2: Trim results.

\begin{tabular}{lccccc}
\hline$v_{\mathrm{t}}(\mathrm{m} / \mathrm{s})$ & Model type & $\theta(\mathrm{deg})$ & $\delta_{\text {col }}(\mathrm{deg})$ & $\delta_{\mathrm{loN}}(\mathrm{cm})$ & $m_{\mathrm{c}}(\mathrm{Nm})$ \\
\hline \multirow{2}{*}{0} & Single-body & 2.6102 & 2.2694 & 0.8925 & - \\
& Multibody & 2.6159 & 2.2694 & 0.8945 & 4030 \\
\hline \multirow{2}{*}{10} & Single-body & 2.1558 & 1.5679 & 2.0581 & - \\
& Multibody & 2.1609 & 1.5676 & 2.06 & 3368 \\
\hline \multirow{2}{*}{20} & Single-body & 1.0758 & 0.1024 & 2.8362 & - \\
& Multibody & 1.0793 & 0.1016 & 2.8376 & 1876 \\
\hline \multirow{2}{*}{30} & Single-body & -0.0267 & -0.9137 & 3.3743 & - \\
& Multibody & -0.0242 & -0.9147 & 3.3754 & 420 \\
\hline \multirow{2}{*}{40} & Single-body & -0.9632 & -1.3051 & 3.9133 & - \\
& Multibody & -0.9612 & -1.3064 & 3.914 & -756 \\
\hline \multirow{2}{*}{50} & Single-body & -1.7255 & -1.208 & 4.6349 & - \\
& Multibody & -1.7242 & -1.2091 & 4.6351 & -1664 \\
\hline \multirow{2}{*}{60} & Single-body & -2.5659 & -0.4407 & 5.6443 & - \\
& Multibody & -2.5648 & -0.4422 & 5.6441 & -2936 \\
\hline
\end{tabular}

based on the single-body model can be described as follows: find the appropriate $\delta_{\mathrm{loN}}, \delta_{\text {col }}$, and $\theta$ to make $f_{x}, f_{z}$, and $m_{y}$ approach zeros. Again, the default algorithm of the "fmincon" function of "Matlab" software can solve the problem.

In the helicopter configuration, the longitudinal trims are calculated using the multibody model and single-body model at various flight speeds. The results are shown in Table 2.

As shown in Table 2, the trim results of the XV-15 based on two models are close at various flight speeds. The difference of trim results is the motor torque acting on the nacelle $m_{c}$. The trim results of the multibody model contain the torque. The value of $m_{c}$ tells us the amount of torque needed to maintain the nacelle inclination angle of 90 degrees, which can be treated as the disturbance torque when the rotation of the nacelle is controlled as shown in Section 5.

4.2. Longitudinal Trim Based on the Multibody Model at Various Nacelle Angles. As the nacelle inclination angle changes from 90 degrees to 0 degrees, the XV-15 gradually

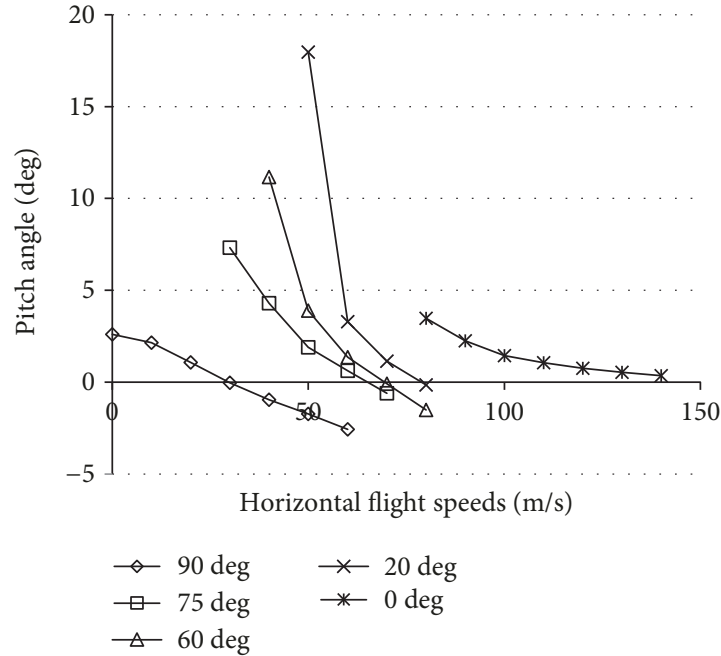

FIgUre 2: Euler pitch angle of the body.

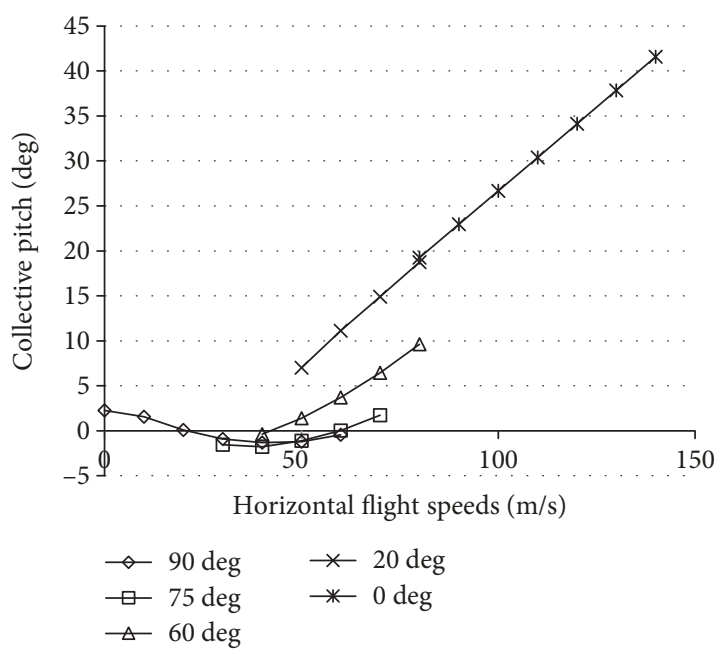

Figure 3: Collective pitch of the rotors.

changes from helicopter configuration to fixed-wing plane configuration. We find the right amount of longitudinal manipulation (longitudinal cyclic pitches of rotors and elevator deflection angle) and Euler pitch angle so that the XV-15 remains longitudinally stable and constant speed at different nacelle inclinations and different flight speeds. The trim results are shown in Figures 2-5. From these figures, we can find some interesting facts which verify that the aerodynamic calculation part of the multibody model coincides with the actual flight of a tilt-rotor aircraft. These facts include the following: (1) in helicopter configuration, the forward component of the rotor thrust is used to overcome the air drag force. As the flight speed increases, the Euler pitch angle of XV-15 also decreases to obtain more forward rotor thrust. (2) in helicopter configuration, as the forward flight speed increases, the collective pitch of the rotors appears to decrease firstly and then increase.

The trim results of the XV-15 in the helicopter mode obtained using the model are compared with the results of 


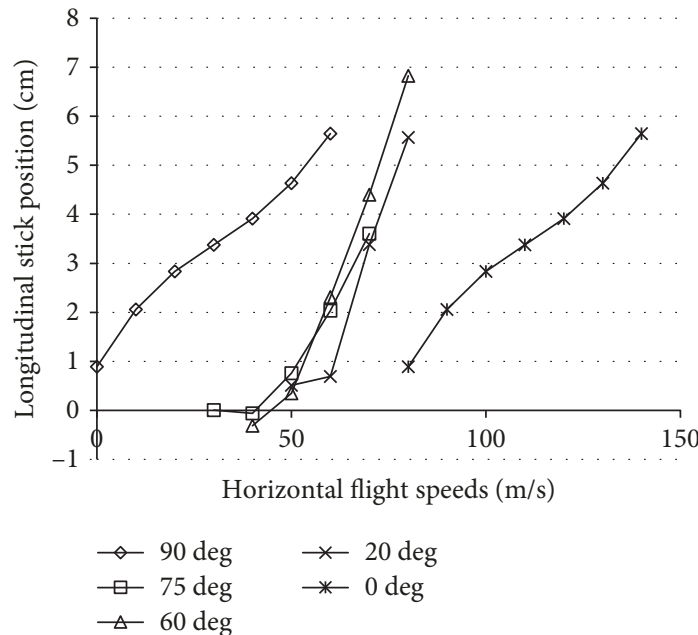

FIgURE 4: Longitudinal stick position.

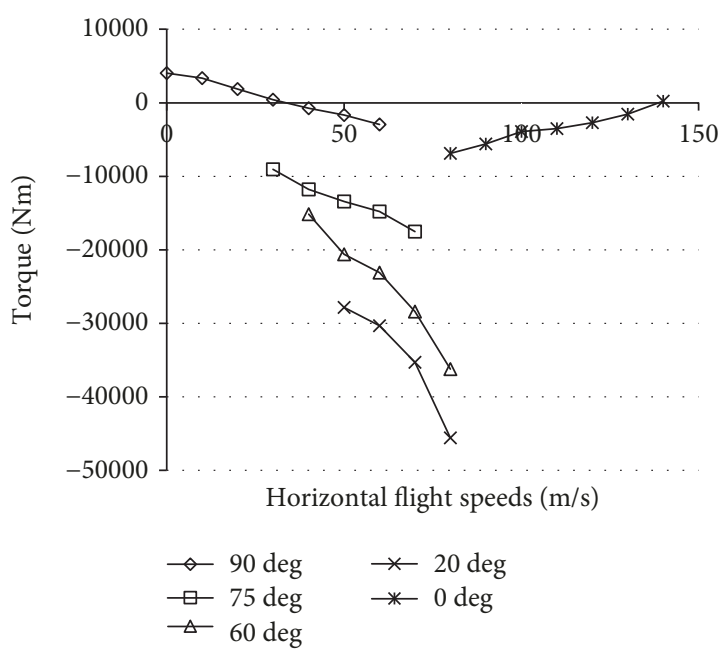

Figure 5: Nacelle torque from the body.

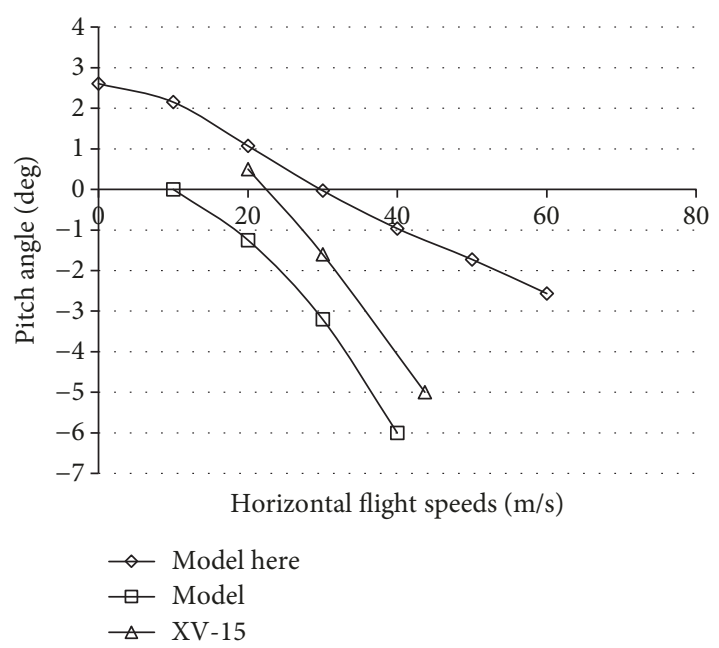

FIGURE 6: Euler pitch angle in helicopter configuration.

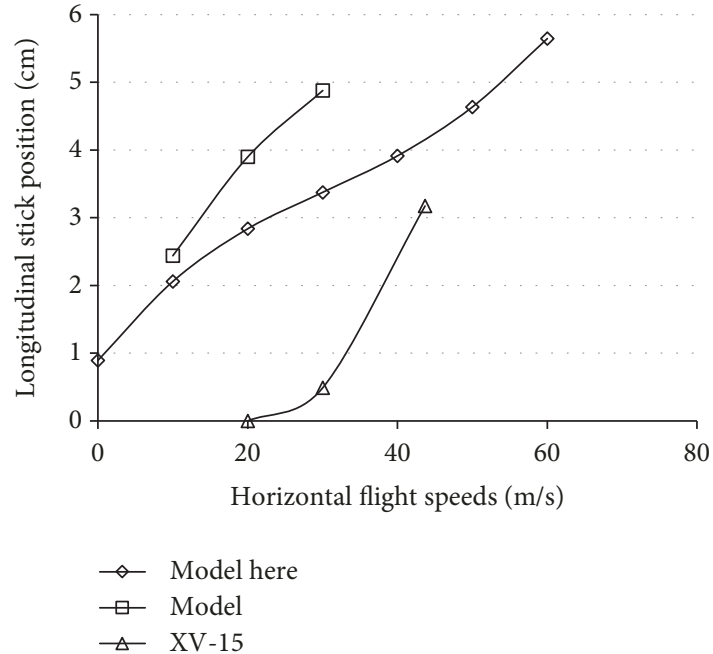

FIgURE 7: Longitudinal stick position in helicopter configuration.

the model in Ref. [18] and the XV-15 flight test data [18], as shown in Figures 6 and 7. The label "model here" represents the trim results using the model in this paper, the label "model" represents the trim results using the model in Ref. [18], and the label "XV-15" represents the flight test data of the XV-15. The difference in the trim results is mainly due to the different aerodynamic calculation models and the error relative to the aerodynamic of the XV-15.

\section{Euler Angles and Nacelle Inclination Angle Control of XV-15 Using the Multibody Model}

In this section, we show how the multibody model can be used for the control of Euler angles and nacelle inclination angle of the XV-15. In a common study of tilt-rotor aircraft attitude control, the control of the nacelle tilting is not considered [9-12]. Using the multibody model, the dynamic process of the nacelle inclination angle is described, and the control algorithm of the nacelle inclination angle is presented.

A model inversion control architecture shown in Figure 8 can be used to track the Euler angle command based on the single-body model of the XV-15 [9]. Replacing the single-body model with the multibody model, the nacelle inclination angle command can be tracked additionally. In Figure 8, only the signal of the nacelle inclination angle is drawn, and the Euler angle control channels are consistent with it.

The model inversion control is based on the linearized dynamics at $10 \mathrm{~m} / \mathrm{s}$ airspeed in helicopter configuration. The linearized multibody model is shown in

$$
\left[\begin{array}{c}
\dot{p} \\
\dot{q} \\
\dot{r} \\
\dot{\omega}
\end{array}\right]=A_{1}\left[\begin{array}{c}
u \\
v \\
w
\end{array}\right]+A_{2}\left[\begin{array}{c}
p \\
q \\
r
\end{array}\right]+A_{3}\left[\begin{array}{c}
\theta_{\mathrm{N}} \\
\delta_{\mathrm{col}}
\end{array}\right]+B\left[\begin{array}{c}
\delta_{\mathrm{lat}} \\
\delta_{\mathrm{loN}} \\
\delta_{\mathrm{ped}} \\
m_{\mathrm{c}}
\end{array}\right],
$$




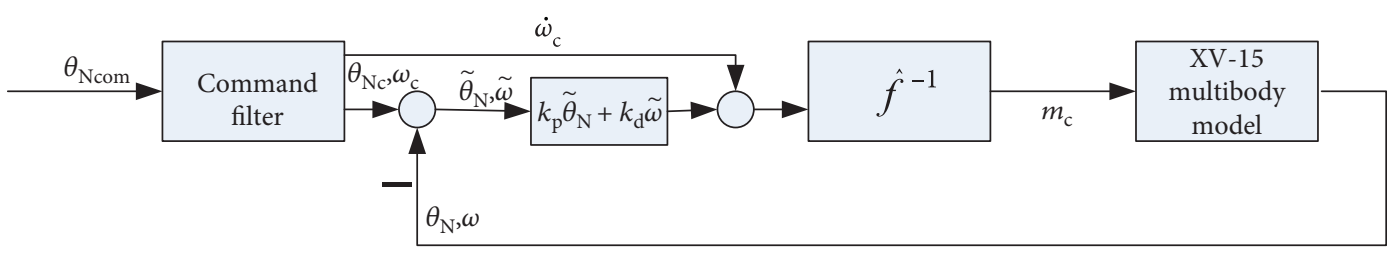

FIGURE 8: Model inversion architecture for nacelle inclination angle command tracking.

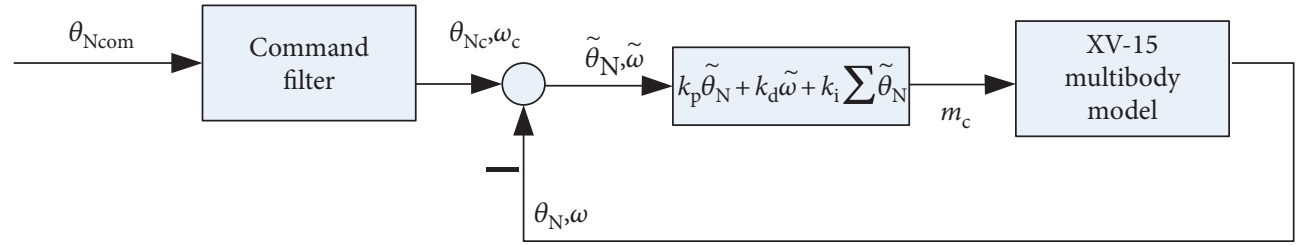

FIGURE 9: PID architecture for nacelle inclination angle command tracking.

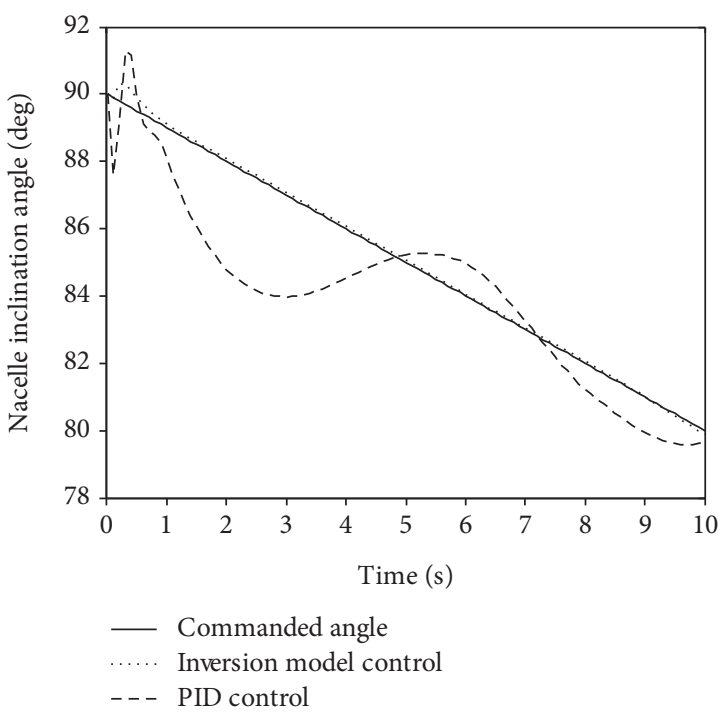

FIGURE 10: Nacelle inclination angle tracking.

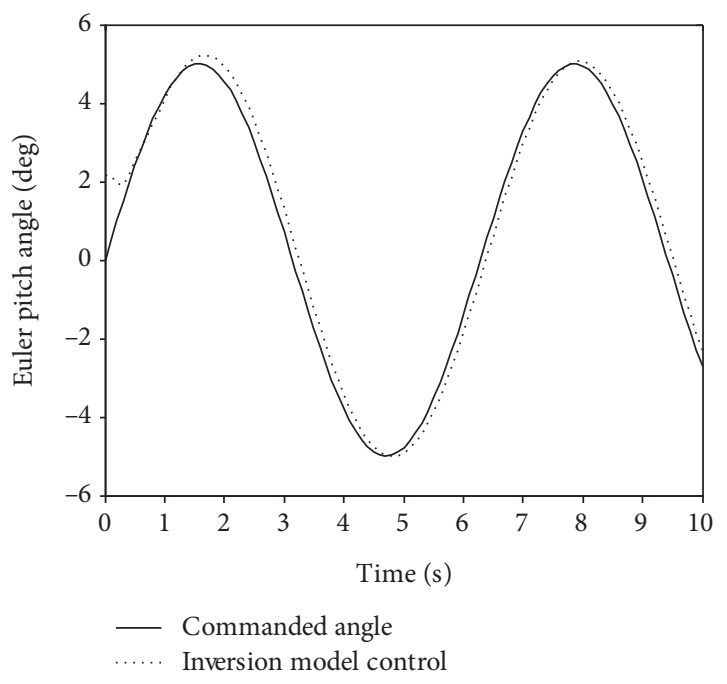

FIGURE 11: Euler pitch angle tracking. where $A_{1}, A_{2}, A_{3}$, and $B$ represent the aerodynamic stability and control derivatives at the nominal operating point. The block $\widehat{f}^{-1}$ in Figure 8 represents the inversion model in

$$
\left[\begin{array}{c}
\delta_{\mathrm{lat}} \\
\delta_{\mathrm{loN}} \\
\delta_{\mathrm{ped}} \\
m_{\mathrm{c}}
\end{array}\right]=B^{-1}\left(\left[\begin{array}{c}
\dot{p} \\
\dot{q} \\
\dot{r} \\
\dot{\omega}
\end{array}\right]-A_{1}\left[\begin{array}{l}
u \\
v \\
w
\end{array}\right]-A_{2}\left[\begin{array}{l}
p \\
q \\
r
\end{array}\right]-A_{3}\left[\begin{array}{l}
\theta_{\mathrm{N}} \\
\delta_{\mathrm{col}}
\end{array}\right]\right) .
$$

In order to verify the usefulness of the architecture based on the multibody model, the simulation of the initial tilting from helicopter configuration to fixed-wing configuration is carried out. The nacelle inclination angle is tilted from $90^{\circ}$ to $80^{\circ}$ at a speed of $1 \mathrm{deg} / \mathrm{s}$ for $10 \mathrm{~s}$. In order to show that the control of the Euler pitch angle is decoupled from the nacelle inclination angle, a cycle command for the Euler pitch angle is tracked. For comparison, a simple PID controller used in the nacelle inclination angle channel is shown in Figure 9. The nacelle inclination angle track result is shown in Figure 10, and the pitch angle track result is shown in Figure 11.

In Figure 10, the solid line represents the change of the nacelle inclination angle control command over time, the long dotted line represents the actual change of the nacelle inclination angle under a model inversion control architecture, and the dotted line represents the actual change of the nacelle inclination angle under a PID control architecture. The long dotted line matches the solid line better than the dotted line. The model inverse control is better for tracking the nacelle inclination angle command. The change of the nacelle inclination angle is related to many factors, including longitudinal manipulation, nacelle inclination angle, airspeed, Euler pitch angle, and control torque. In the model inverse tracking control of the nacelle inclination angle, the control torque is corrected in advance by using the model parameters and state feedback, and a better control effect is obtained. In Figure 11, the solid line 
represents the change of the Euler pitch angle command of the XV-15, and the long dotted line represents the actual change of the Euler pitch angle command of the XV-15 under the model inversion control architecture. The control of the Euler pitch angle and nacelle inclination angle is decoupling under the model inversion control architecture.

\section{Conclusion}

Multibody models can characterize the motion of a tilt-rotor aircraft more realistically than a single-body model. In this paper, we focus on the motion coupling of the nacelles and the body of a tilt-rotor aircraft and establish a multibody model to characterize the interaction and rotation of them. The model is applied to track the nacelle inclination angle command under a model inversion control architecture. Through calculation, simulation, and analysis, the following conclusions are obtained:

(1) Taking the XV-15 tilt-rotor aircraft as an example, the longitudinal trim calculation is carried out by using the single-body model and multibody model. The results of the trim are in good agreement, which shows the correctness of the multibody model derivation process in this paper

(2) Compared to the single-body model, the multibody model has the ability to characterize the interaction between the body and the nacelle of a tilt-rotor aircraft. When it is used to control the nacelle inclination angle and the Euler attitude angles of the body, it provides a priori information of the nacelle disturbance torque, thereby improving the accuracy of the nacelle inclination control

The multibody model in this paper shows the potential for an active control of nacelle tilting. The active control of nacelle tilting is beneficial to the smoothing of the tilting process.

\section{Nomenclature}

l: $\quad$ Distance between the pivot and center of gravity (c.g.) of the nacelle $(\mathrm{m})$

$x_{\mathrm{p}}: \quad x$ position (longitudinal) of the pivot in the body axis with respect to the body c.g. (m)

$z_{\mathrm{p}}: \quad z$ position (vertical) of the pivot in the body axis with respect to the body c.g. $(\mathrm{m})$

$u$ : $\quad x$ velocity (longitudinal) of the body c.g. in the body axis with respect to the air $(\mathrm{m} / \mathrm{s})$

$v$ : $\quad y$ velocity (lateral) of the body c.g. in the body axis with respect to the air $(\mathrm{m} / \mathrm{s})$

$w$ : $\quad z$ velocity (vertical) of the body c.g. in the body axis with respect to the air $(\mathrm{m} / \mathrm{s})$

p: $\quad$ Body axis roll rate $(\mathrm{rad} / \mathrm{s})$

$q$ : $\quad$ Body axis pitch rate $(\mathrm{rad} / \mathrm{s})$

$r$ : $\quad$ Body axis yaw rate $(\mathrm{rad} / \mathrm{s})$

$\omega$ : Tilting speed of the nacelle with respect to the body ( $\mathrm{rad} / \mathrm{s})$

$\phi: \quad$ Euler roll angle (rad) $\theta: \quad$ Euler pitch angle (rad)

$\psi$ : $\quad$ Euler yaw angle (rad)

$\theta_{\mathrm{N}}$ : Nacelle inclination angle ( 0 deg corresponds to airplane configuration; 90 deg corresponds to helicopter configuration) (rad)

$f$ : Components of the sum of the aerodynamics force and gravity of the body or the nacelles in the body axis $(\mathrm{N})$

$m$ : Components of the sum of the aerodynamics moment of the body or the nacelles about the body or the nacelle c.g. and motor torque in the body axis $(\mathrm{N} \cdot \mathrm{m})$

I: $\quad$ Components of the moment of inertia of the body or the nacelles about body c.g. or nacelle c.g. $\left(\mathrm{kg} \cdot \mathrm{m}^{2}\right)$

$m_{\mathrm{c}}$ : Motor torque acting on the nacelle ( + corresponds to the nacelle rise) $(\mathrm{N} \cdot \mathrm{m})$

$v_{\mathrm{t}}$ : Total linear velocity of the aircraft c.g. with respect to the air $(\mathrm{m} / \mathrm{s})$

$\delta_{\text {col }}$ : Root collective pitch of the rotors (deg)

$\delta_{\text {lat }}$ : Lateral stick position $(\mathrm{cm})$

$\delta_{\text {loN }}$ : Longitudinal stick position $(\mathrm{cm})$

$\delta_{\text {ped }}:$ Pedal stick position $(\mathrm{cm})$

$m_{\mathrm{B}}$ : Mass of the body $(\mathrm{kg})$

$m_{\mathrm{N}}$ : Mass of the nacelle $(\mathrm{kg})$.

Subscripts

$\mathrm{B} x$ : $x$ component of the body

By: $y$ component of the body

$\mathrm{B} z$ : $z$ component of the body

$\mathrm{N} x: x$ component of the nacelles

$\mathrm{N} y$ : $y$ component of the nacelles

$\mathrm{N} z: z$ component of the nacelles.

\section{Data Availability}

More paremeters of the XV-15 tiltrotor can be found in ref. [2].

\section{Conflicts of Interest}

The authors declare that they have no conflicts of interest.

\section{Acknowledgments}

This research is supported by the Science and Technology Planning Project of Guangdong Province of China under grant no. 2017A020208063 and the Science and Technology Program of Guangzhou, China, under grant no. 201804010384.

\section{References}

[1] H. Rosenstein, M. A. McVeigh, and P. A. Mollenkof, "Mathematical model for a real time simulation of a tilt rotor aircraft," Tech. Rep. NASA CR-114601, 1973.

[2] S. W. Ferguson, "A mathematical model for real time flight simulation of a generic tilt-rotor aircraft," Tech. Rep. NASA CR-166536, 1988.

[3] M. Miller and J. Narkiewicz, "Titlrotor modeling for simulation in various flight conditions," Journal of Theoretical and Applied Mechanics, vol. 44, no. 4, pp. 881-906, 2006. 
[4] L. Haixu, Q. Xiangju, and W. Weijun, "Multi-body motion modeling and simulation for tilt rotor aircraft," Chinese Journal of Aeronautics, vol. 23, no. 4, pp. 415-422, 2010.

[5] J. P. Mueller, Y. Gourinat, R. Ferrer, T. Krysinski, and B. Kerdreux, "A numerical study on active control for tiltrotor whirl flutter stability augmentation," in Proceedings of American Helicopter Society 4th Decennial Specialist's Conference on Aeromechanics, Fisherman's Wharf, pp. 275-293, San Francisco, CA, USA, January 2004.

[6] V. Muscarello and G. Quaranta, "Wing-pilot vertical bounce in tiltrotors," Journal of Guidance, Control, and Dynamics, vol. 41, no. 8, pp. 1731-1743, 2018.

[7] M. Mattaboni, P. Masarati, G. Quaranta, and P. Mantegazza, "Multibody simulation of integrated tiltrotor flight mechanics, aeroelasticity and control," Journal of Guidance, Control, and Dynamics, vol. 35, no. 5, pp. 1391-1405, 2012.

[8] M. Mattaboni, P. Masarati, and P. Mantegazza, "Multibody simulation of a generalized predictive controller for tiltrotor active aeroelastic control," Proceedings of the Institution of Mechanical Engineers, Part G: Journal of Aerospace Engineering, vol. 226, no. 2, pp. 197-216, 2011.

[9] R. T. Rysdyk and A. J. Calise, "Adaptive model inversion flight control for tilt-rotor aircraft," Journal of Guidance, Control, and Dynamics, vol. 22, no. 3, pp. 402-407, 1999.

[10] T. Yomchinda, J. Horn, and N. Cameron, "Integrated flight control design and handling qualities analysis for a tilt rotor aircraft," in AIAA Atmospheric Flight Mechanics Conference, p. 6058, Chicago, IL, USA, August 2009.

[11] R. Mehra, M. Wasikowski, R. Prasanth, R. Bennett, and D. Neckels, "Model predictive control design for XV-15 tilt rotor flight control," in AIAA Guidance, Navigation, and Control Conference and Exhibit, p. 4331, Montreal, Canada, August 2001.

[12] B. M. Kim, B. S. Kim, and N. W. Kim, "Trajectory tracking controller design using neural networks for a tiltrotor unmanned aerial vehicle," Proceedings of the Institution of Mechanical Engineers, Part G: Journal of Aerospace Engineering, vol. 224, no. 8, pp. 881-896, 2010.

[13] G. Bernardini, C. Testa, and M. Gennaretti, "Tiltrotor cabin noise control through smart actuators," Journal of Vibration and Control, vol. 22, no. 1, pp. 3-17, 2016.

[14] R. Singh, F. Gandhi, J. Paik, and E. Hathaway, "Active tiltrotor whirl-flutter stability augmentation using wing-flaperon and swash-plate actuation," Journal of Aircraft, vol. 44, no. 5, pp. 1439-1446, 2007.

[15] T. R. Kane and D. A. Levinson, "Formulation of equations of motion for complex spacecraft," Journal of Guidance, Control, and Dynamics, vol. 3, no. 2, pp. 99-112, 1980.

[16] P. D. Talbot, B. E. Tinling, W. A. Decker, and R. T. N. Chen, "A mathematical model of a single main rotor helicopter for piloted simulation," Tech. Rep. NASA TM-84281, 1982.

[17] W. Johnson, Helicopter Theory, Princeton University Press, Princeton, NJ, USA, 1980.

[18] K. M. Kleinhesselink, Stability and Control Modeling of Tiltrotor Aircraft, University of Maryland, College Park, MD, USA, 2007. 


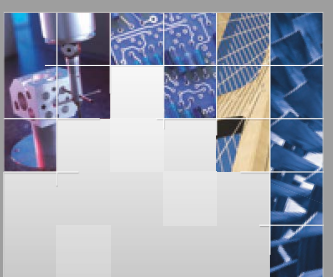

\section{Enfincering}
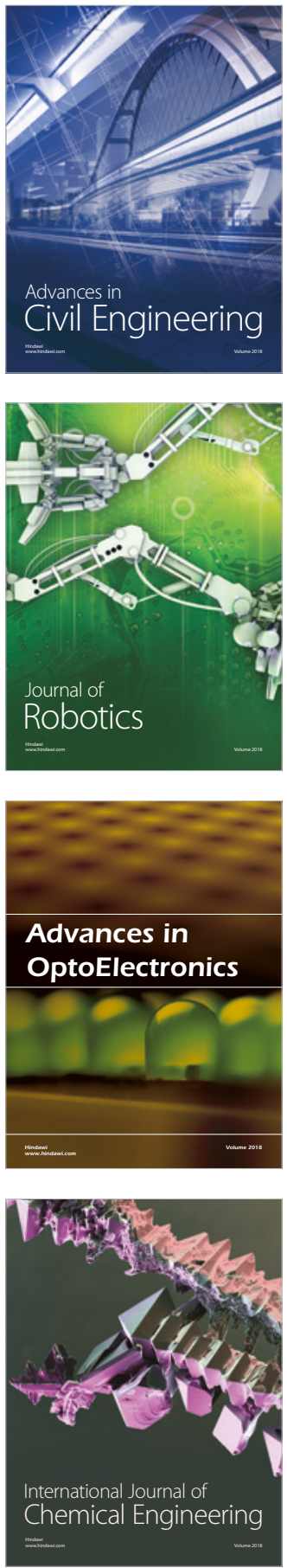

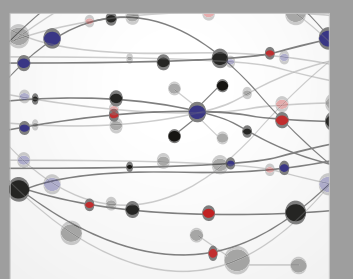

\section{Rotating \\ Machinery}

The Scientific World Journal

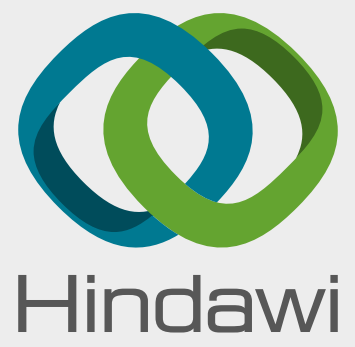

Submit your manuscripts at

www.hindawi.com
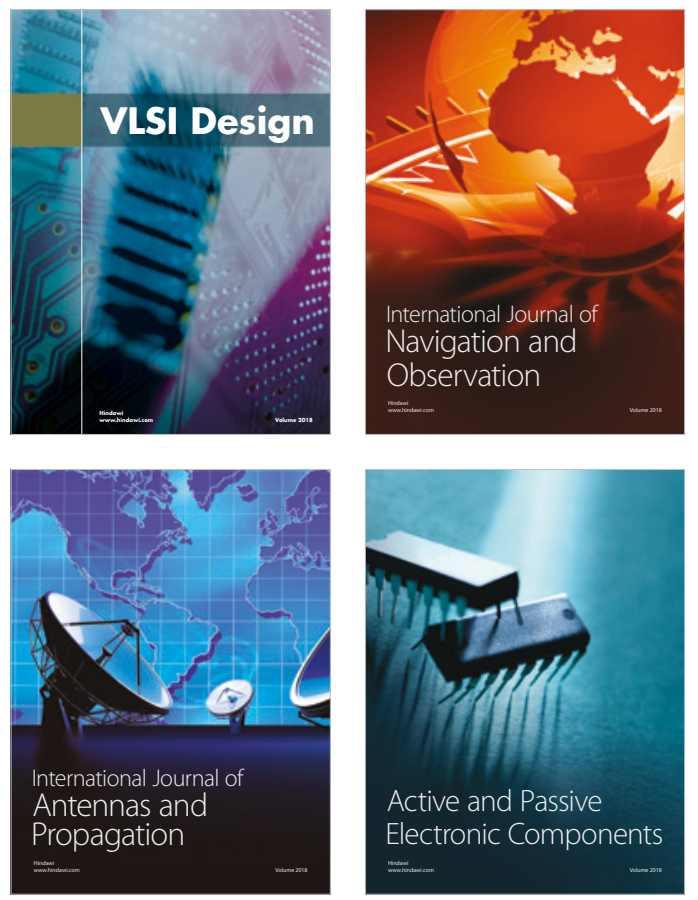
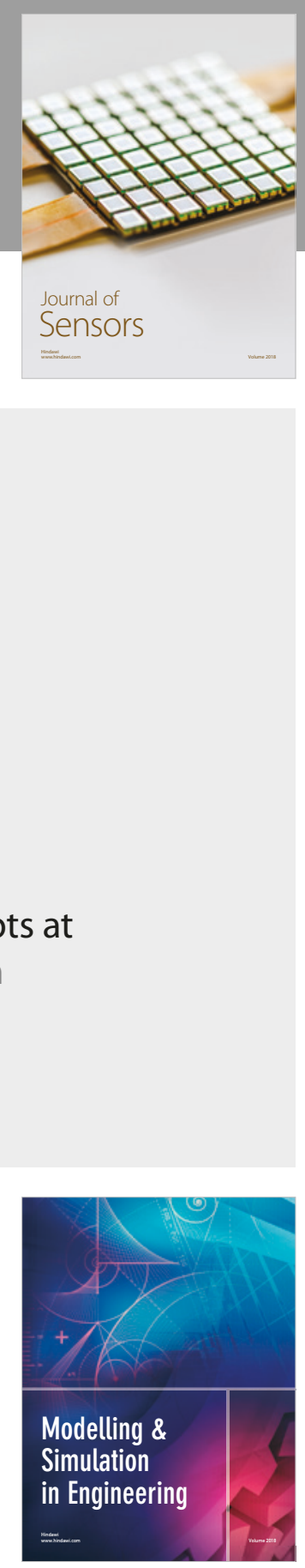

\section{Advances \\ Multimedia}
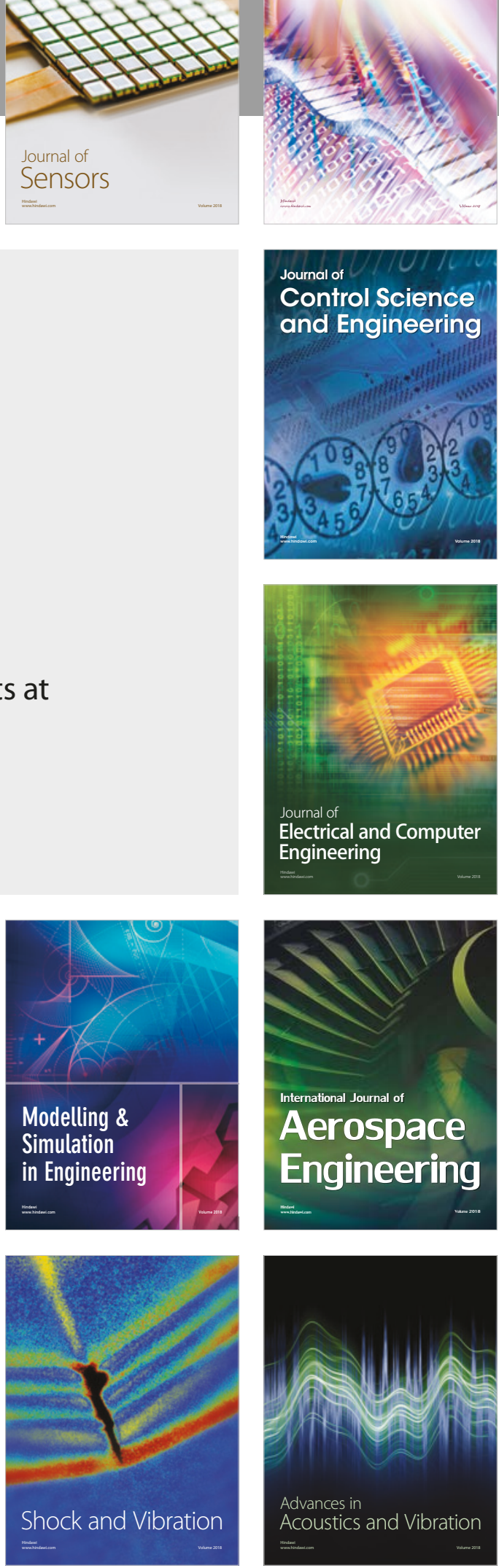